Manuscript Number:

Title: Prevention of radiotherapy-induced neurocognitive dysfunction in survivors of paediatric brain tumours - the potential role of modern imaging and radiotherapy techniques

Article Type: Review (Invited)

Keywords: "brain tumours", "radiotherapy", "imaging", "functional mapping", "diffuse tensor imaging", "fibre tracking", "intensitymodulated", "proton beam", "MRI-Linac", "IGRT", "VMAT", "Tomotherapy"

Corresponding Author: Dr. Thankamma V Ajithkumar, MD, MRCP, FRCR

Corresponding Author's Institution: Cambridge University Hospitals NHS Foundation Trust

First Author: Thankamma V Ajithkumar, MD, MRCP, FRCR

Order of Authors: Thankamma V Ajithkumar, MD, MRCP, FRCR; Stephen Price, PhD FRCS (Neuro.Surg); Gail Horan, MRCPI, FRCR; Amos Burke, PhD, FRCPCH; Sarah Jefferies, PhD, FRCR

Manuscript Region of Origin: UNITED KINGDOM

Abstract: Neurocognitive dysfunction is the leading cause of reduced quality of life in the long-term survivors of paediatric brain tumours. Radiotherapy is one of the significant contributors to neuro-cognitive sequelae. The current approaches in prevention and/or reduction in neurocognitive dysfunction include avoidance of radiotherapy in young children and reduction of radiotherapy dose and volume of brain irradiated. There have been considerable advances in brain imaging, especially with functional imaging and fibre tracking using diffusion tensor imaging. Radiotherapy techniques for photon therapy have also evolved in recent years with the wide-spread use of techniques such as image-guided radiotherapy (IGRT), volumetric modulated arc therapy (VMAT), helical tomotherapy, and adaptive radiotherapy (ART). The number of proton beam therapy facilities is increasing globally and there is a great enthusiasm for the clinical use of newly developing MRI-guided radiotherapy systems. We review the potential role of modern imaging and innovative radiotherapy techniques in minimising neurocognitive sequelae in children with brain tumours and various strategies to integrate these advances to drive further research. 
Review article

\title{
Prevention of radiotherapy-induced neurocognitive dysfunction in survivors of paediatric brain tumours - the potential role of modern imaging and radiotherapy techniques
}

\author{
Thankamma Ajithkumar MD, FRCR ${ }^{1}$ \\ Stephen Price PhD FRCS (Neuro.Surg) ${ }^{2}$ \\ Gail Horan MRCPI, FRCR ${ }^{1}$ \\ Amos Burke PhD, FRCPCH ${ }^{3}$ \\ Sarah Jefferies PhD, FRCR ${ }^{1}$
}

1. Consultant Clinical Oncologist, Cambridge University Hospitals NHS Foundation Trust, Cambridge Biomedical Campus, Hills Road, Cambridge CB2 0QQ, UK.

2. Consultant Neurosurgeon, Cambridge University Hospitals NHS Foundation Trust, Cambridge Biomedical Campus, Hills Road, Cambridge CB2 0QQ, UK.

3. Consultant Paediatric Oncologist, Cambridge University Hospitals NHS Foundation Trust, Cambridge Biomedical Campus, Hills Road, Cambridge CB2 0QQ, UK.

Address for correspondence

T Ajithkumar

Department of Oncology

Cambridge University Hospitals Foundation Trust

Box 193

Hills Road

Cambridge CB2 0QQ

Phone: 00441223274401

Fax: 00441223217094

Email: Thankamma.ajithkumar@addenbrookes.nhs.uk

Brief title: Prevention of neuro-cognitive dysfunction in brain tumours 


\begin{abstract}
Neurocognitive dysfunction is the leading cause of reduced quality of life in the long-term survivors of paediatric brain tumours. Radiotherapy is one of the significant contributors to neuro-cognitive sequelae. The current approaches in prevention and/or reduction in neurocognitive dysfunction include avoidance of radiotherapy in young children and reduction of radiotherapy dose and volume of brain irradiated. There have been considerable advances in brain imaging, especially with functional imaging and fibre tracking using diffusion tensor imaging. Radiotherapy techniques for photon therapy have also evolved in recent years with the wide-spread use of techniques such as image-guided radiotherapy (IGRT), volumetric modulated arc therapy (VMAT), helical tomotherapy, and adaptive radiotherapy (ART). The number of proton beam therapy facilities is increasing globally and there is a great enthusiasm for the clinical use of newly developing MRI-guided radiotherapy systems. We review the potential role of modern imaging and innovative radiotherapy techniques in minimising neurocognitive sequelae in children with brain tumours and various strategies to integrate these advances to drive further research.
\end{abstract}

\title{
Search strategy and selection criteria
}

References for this review were identified through searches of PubMed with the search terms "brain tumours", "radiotherapy", "imaging", "functional mapping", "diffuse tensor imaging", "fibre tracking", "intensity-modulated", "proton beam", "MRI-Linac", "IGRT", "VMAT", "Tomotherapy" from 1990 to June 2016. Only papers published in English were reviewed. The final reference list was generated on the basis of originality and relevance to the broad scope of this review. 


\section{Introduction}

Brain tumours, the most common solid tumours in children, constitute more than $20 \%$ of paediatric cancers $(1,2)$. With the current advances in treatment, more than $70 \%$ of children are long-term survivors (3). Almost a half of paediatric patients will develop progressive neurological deficits (4). This is reflected in lack of attainment of academic and professional potential (5).

The development of neurocognitive dysfunction is contributed to by a number of disease-, treatment- and host-related factors such as location and size of the tumour, age at diagnosis, surgery, radiotherapy, chemotherapy, and premorbid intellectual and neurological function (6). Studies also suggest that genetic effects may influence various elements of cognitive function (7).

Radiotherapy is one of the major contributing factors to neuro-cognitive dysfunction, which is typically progressive in nature $(5,8)$. Cognitive dysfunction can affect four main domains: global cognitive functioning (IQ), academic achievements, executive function, and psychomotor skills $(6,9)$. Prevention or minimization of radiation-induced cognitive dysfunction has been a topic of intense research for a long time. The only measures which have achieved some success to date are avoidance of radiotherapy in young children, especially less than three years of age and reduction in the total radiation dose and volume of brain irradiated $(10,11)$.

Recently, there have been considerable advances in brain imaging, particularly with functional mapping and fibre tracking using diffusion tensor imaging (12). Some of these advances are being exploited in the surgical management of brain tumours and radiosurgery (13-16). However, integration of these technologies to improve radiotherapy planning is slow. In this article, we review the role of modern imaging in understanding neurocognitive dysfunction, discuss the potential role for imaging and innovative radiotherapy techniques in minimising neurocognitive sequelae, and derive inspirational strategies to integrate these advances to drive further research.

\section{Mechanisms of radiation-induced neurocognitive dysfunction}

Radiotherapy can damage progenitor cells, inflammatory and stromal cells, and vasculature (17). Radiotherapy induced inflammation, angiogenesis and cell death can lead to white and grey matter damage (9). Both white and grey matter development depends on the age of the individual and full myelination of the cerebral cortex is achieved only in early adulthood. In adults, neurocognitive dysfunctions are irreversible and progressive, affecting particularly the domains of processing speed and memory and in severe cases leading to ataxia, urinary incontinence, and dementia in $2-5 \%(18,19)$. In children, radiotherapy can prevent ageappropriate normal maturation and myelination of brain and/or damage to white matter tracts (20). The molecular effects of radiotherapy-induced cognitive dysfunction have been reviewed recently (21). 


\section{Impact of radiotherapy parameters}

The risk and severity of neurocognitive dysfunction depends on a number of patient-and disease-related factors and radiotherapy parameters. Studies show that the risk of neurocognitive dysfunction increases with increasing dose of radiotherapy, with a progressive deterioration over time $(22,23)$. Radiotherapy prevents children acquiring new skills and knowledge, leading to progressive worsening of deficit over time (5). In a meta-analysis, cranial radiotherapy, chemotherapy and longer time since diagnosis were associated with lower general intelligence (24). Children with infratentorial tumours and younger age have a higher risk of neurocognitive dysfunction $(8,25)$. Children under 3 years are particularly vulnerable to deleterious effects of radiotherapy due to rapid cell proliferation and myelination and dendritic and axonal outgrowth and radiotherapy is generally avoided in this age group $(10,24)$.

\section{Eloquent brain areas and domains in neuro-cognition}

A number of areas are important in neuro-cognition, but the relative contribution of individual areas in overall cognition is still to be fully understood. Neurons and glial cell are produced from the neurogenic stem cells located in the subventricular zone of the lateral ventricles and subgranular zone of the hippocampal gyrus (26). These areas are part of the limbic system and continuous renewal of neurons from the stem cells is important in memory (27). The limbic system consists of hippocampus, parahippocampal gyrus, and amygdaloid. These structures located in the temporal lobe are important in various aspects of memory and emotional learning. In a study of 32 children treated with proton therapy, even though neurocognitive function is relatively spared, children less than 7 years and those who received a higher dose to the left temporal lobe or hippocampus had worse neuro-cognitive dysfunction (28).

The frontal pole, anterior cingulate and frontal white matter horn are important in working memory and executive function, whereas the corpus callosum is involved in cognition and processing speed $(29,30)$. The stem cells within the subventricular zone (SVZ) are important in injury repair and thereby maintain the ability for life-time learning $(31,32)$. The hippocampus which forms part of the limbic system is involved in the consolidation of new memory (33-35). While the impact of radiation to these areas is not correlated with neurocognitive dysfunction in prospective studies, a number of studies in adults with brain metastases have shown that with sparing of the hippocampi, the incidence of neuro-cognitive sequelae can be significantly reduced (36). However, the role of hippocampal sparing to preserve cognitive function in children is yet to be studied and it is not certain that a simple sparing of the hippocampus, which measures approximately $1 \%$ of total brain volume, would be sufficient to prevent neurocognitive dysfunction in children (32). It is also unknown whether sparing of a unilateral hippocampus has an impact on preservation of cognition. Studies of metastatic brain tumours in adults suggest that the risk of recurrence in the hippocampal region is low and therefore hippocampal sparing is a feasible option without 
compromising local control of disease $(37,38)$. However, neither the true incidence of hippocampal spread nor the risk of disease recurrence in the hippocampal region in paediatric brain tumours is known.

The neurons from the cerebellum form a series of closed loops with neurons in the prefrontal cortex, temporal lobes and limbic structures. Damage to these neurons could lead to the postoperative sequelae of posterior fossa syndrome (cerebellar mutism) in medulloblastoma and also to late neurocognitive dysfunction $(39,40)$.

\section{Conventional imaging in neurocognitive dysfunction}

Conventional anatomical MRI changes include white matter changes, mild enhancement, and oedema in the distribution of the radiation field (17). Diffuse white matter changes (often referred to as leucoencephalopathy) develop in $16 \%$ of children treated with radiotherapy for malignant brain tumours after a median interval of 7.8 months (41). These lesions were most commonly seen in the pons and cerebellum and $73 \%$ of lesions fully resolved after a median interval of 6.2 months (41). In children with acute lymphoblastic leukaemia (ALL) who were only treated with chemotherapy, white matter changes were found in $10 \%$ at the end of treatment and in $12 \%$ of patients at 5 years (42). Although a minority of patient with these white matter lesions develop permanent neurological deficits, the development of these lesions appears to be a poor predictor of neurocognitive deficits (41-43).

It is recognised that volumetric measurement of the brain can identify global atrophy and that chemoradiotherapy in adults with brain tumours results in loss of brain volume (44). Studies correlating global brain volume changes have failed to show any association in adult survivors of paediatric brain tumours (45).

It is clear that conventional MR methods are not sensitive enough to identify changes that predict neurocognitive dysfunction. The development of new imaging methods sensitive to pathological alteration will allow better understanding of these changes.

\section{Importance of white matter structures on neurocognitive decline}

Studies that measure changes in white matter volume have shown that decrease in white matter volume following radiotherapy correlates with IQ decline and neurocognitive decline (46-49). Voxel based morphometry approaches show that frontal white matter (especially right sided) is more sensitive to volume loss than other parts of the brain (48). Increased white matter volume loss is associated with intensity of CNS treatment (i.e. treatment for brain tumours has a greater effect than craniospinal irradiation for ALL), younger age of treatment and the interval between treatment and imaging study (50). 


\section{Advanced MRI techniques for brain imaging}

\section{Functional MRI using BOLD imaging}

Functional MRI (fMRI) is a well-established technique to identify cortical areas that are activated undertaking a specific task. During cortical activation there is a transient, focal increase in blood flow that can be measured by differences in the magnetic properties of haemaglobin depending on its oxygenation status. Deoxyhaemaglobin is paramagnetic and as a result shortens the $\mathrm{T} 2 *$ of the blood and its surroundings. Oxyhaemaglobin is diamagnetic, and as a result increasing oxygenation of blood reduces the $\mathrm{T} 2 *$ shortening and increases the T2* signal. This 'blood-oxygen-level dependent' (BOLD) contrast can be detected using heavily $\mathrm{T} 2 *$-weighted sequences such as gradient-recalled echo (GRE) and echo planar imaging (EPI). The transient increase in $\mathrm{T} 2 *$ signal during activation is small and detected by statistical analysis. BOLD signal intensity is reduced with increasing age, increasing tumour grade, proximity to tumour, and previous surgery (51-55). The accuracy of the BOLD imaging in detecting areas of activation has been assessed in adults undergoing awake surgery with cortical stimulation. There appears to be very good accuracy of fMRI correctly identifying regions of motor activation as compared to the gold standard of direct cortical stimulation (sensitivity of $87 \%$ and specificity of 88\%) (56). This accuracy decreases with increasing tumour grade (56). Overall the discrepancy between fMRI and cortical areas stimulated were only $6-13.8 \mathrm{~mm}$ (57). All studies suggest $96-100 \%$ of fMRI activated areas were within $2 \mathrm{~cm}$ of cortical stimulation: the difference may be due to registration errors (57). There is reasonable repeatability of motor function.

Language function, however, is not so well localized by BOLD imaging. Studies correlating fMRI activation with cortical stimulation show that sensitivity and specificity are worse than motor ( $80 \%$ and $78 \%$ respectively) (56). As BOLD signal can be affected by proximity to the tumour, even lateralising language function can be affected by the reduced volume of BOLD effect if it is near the tumour and so can be misleading (58). It is clear that use of multiple language tasks improves accuracy. The sensitivity of naming or verb generation on their own is $22 \%$ and $36 \%$ respectively. This improves to $59 \%$ if these tasks are combined (59). The repeatability of detecting language function is very poor - for individual tasks the overlap is 9-26\%. This improves to 39-44\% if they are combined (60). Test-retest accuracy was worse in high-grade tumours compared to low-grade (61).

\section{Resting State fMRI}

The fMRI methods described above are all task based where changes in blood flow are measured during a task and compared to rest. This accounts for a fraction of the brain activity and it was realized that BOLD fluctuations can be identified at rest. By correlating these regions of BOLD activation it is possible to link regions and develop networks. The methodology and background to this technique of resting state fMRI has recently been reviewed (62). There is much interest among cognitive neuroscientists to use this to study brain networks and metrics of this network has been shown to correlate with cognitive 
reserve (63). This has not been used to assess impact of radiotherapy but is an exciting method for future research.

\section{Diffusion tensor imaging of white matter integrity}

Diffusion tensor imaging (DTI) helps to study the integrity of white matter structures. DTI, in which uses a magnetic resonance signal visualizes water movement within axons, has been used to study white matter development in children. Diffusion of water is high along, and low perpendicular to white matter tracts, resulting in an anisotropic diffusion profile. If you could plot the location of a water molecule diffusing through the brain it would be in the shape of an ellipse with the long axis describing the principal axis of diffusion. Tensor calculus can be used to provide quantification of this tensor. The commonest method of quantifying anisotropy uses the fractional anisotropy (FA) value which lies between 0 (for isotropic diffusion, i.e. diffusion is equal in all directions) and 1 (maximum anisotropic diffusion, i.e. along one axis). The degree of anisotropy depends on white matter fibre diameter and density, the myelin sheath, other macromolecular structure that hinder proton diffusion and fibre-tract coherence (64). By linking adjacent 'ellipses' in different voxels using the principal axis it is possible to develop a probabilistic map of white matter tracts (tractography). DTI tractography is useful for characterising the major white matter pathways (65).

Studies have shown that development in cognitive function in children and adolescents correlates with an increase of FA $(66,67)$. Studies looking at the effect of radiotherapy on white matter tract integrity have shown a reduction in FA in white matter of children treated with radiotherapy and this decrease in FA correlates with IQ, tests of neuropsychology function, and school performance $(45,49,68-71)$. The decrease in FA is more noticeable with earlier age radiotherapy and increased radiotherapy dose $(68,70-73)$. The interval between radiotherapy and the DTI study provides differing results, with some studies suggesting it is correlated with reduced FA whilst others found no association $(70,71)$.

What is clear is that some regions of the brain are more sensitive to radiotherapy than others. Studies have shown a greater decrease in FA in the frontal and temporal lobes (74-76). This reduction, especially in the frontal lobes, is greater despite similar doses of radiotherapy (68). Reduction in FA in frontal and parietal lobes is associated with neurocognitive decline (77). Other structures that are affected by radiotherapy include periventricular white matter, corpus callosum, anterior and posterior limbs of the internal capsule, the corona radiate, and fornix $(69,75,78,79)$.

The difficulty with using DTI to study changes in white matter integrity from radiotherapy is that chemotherapy alone can lead to white matter disruption. Studies in patients treated with chemotherapy alone had reduced FA in white matter. Reduction in FA in the corpus callosum was associated with neurocognitive decline, and a reduction in FA in the inferior frontooccipital fasciculus was associated with a diminished motor processing speed (20). Comparing patient groups that received chemotherapy with radiotherapy showed a larger reduction in FA compared with patients treated with chemotherapy alone $(70,80)$. 
Another problem is that changes in FA do not appear to be diagnostic. There are other studies in children reporting a lower FA in several eloquent brain regions, but without any correlating specific neurocognitive dysfunction (69) (table 1).

\section{Advanced radiotherapy techniques}

There are no prospective studies evaluating the role of selecting sparing of various eloquent areas and domains of brain associated with different elements of cognitive function. A retrospective, which has evaluated radiotherapy dose to potential functional targets of cognitive function, has shown that radiotherapy to the corpus callosum, left frontal white matter, right temporal lobe, bilateral hippocampi, subventricular zone and cerebellum affected global cognitive outcome at doses <60 Gy (32).

While, the dose threshold of these different structures for cognitive decline is unknown, the modern radiotherapy technology can effectively spare or minimise radiotherapy to any brain structures. For example, advanced intensity-modulated radiotherapy (IMRT) methods such as volumetric modulated arc therapy (VMAT) and helical tomotherapy are used effectively to spare hippocampi in brain tumours $(36,81-83)$.

The physical advantage of proton therapy in terms of a significant reduction in radiotherapy dose to normal tissues outside the tumour volume could be exploited to reduce the neurocognitive dysfunction following radiotherapy (84). In a study of children with lowgrade glioma treated with proton therapy $(n=32), 12$ had neurocognitive assessment, which did not show any significant declines in Full-Scale Intelligence quotient (FSIQ) at a median of 4.5 years (28). However, dose to the left temporal lobe/hippocampus was associated with decline in cognitive function. In a recent phase II study of proton therapy for medulloblastoma, there was a decline in FSIQ of 1.5 points per year (95\% CI 0.9-2.1) primary due to a decline in processing speed and verbal comprehension (85). However, perception reasoning and working memory were not affected at a median follow-up of 5.2 years. FSIQ declined significantly in children $<8$ years.

While the initial reports of modern radiotherapy techniques and proton therapy are encouraging, none of the studies correlated the radiotherapy dose to different eloquent areas or domains with neurocognitive function.

\section{The potential for integrating modern imaging with novel radiotherapy technique}

Strategies to prevent or minimise radiation-induced neurocognitive dysfunction include avoidance of radiotherapy in children less than 3 years, optimal integration with chemotherapy to minimise the total dose of radiotherapy and/or volume of brain treated, optimal target delineation using better imaging, and use of highly conformal radiotherapy techniques.

Modern radiotherapy planning is based on a conventional MRI scan co-registered with a planning CT scan. The clinical benefit of integration of functional imaging and tractography 
for fractionated radiotherapy planning in brain tumour has not been studied. However, a number of studies have evaluated the role of functional imaging for radiosurgery treatment planning for benign brain conditions, particularly arteriovenous malformations (AVMs) (15, 16, 86, 87). The frequency of motor complications after corticospinal tractographyintegrated-radiosurgery for patients with AVMs involving the basal ganglia and thalamus $(n=24)$ were significantly less compared with a historical cohort $(n=28)$ without tractography integration (4.2\% vs. $17.9 \% \mathrm{p}=0.021)(88)$. There was no significant difference in 4-year AVM obliteration rate (69\% vs. $76 \%, \mathrm{p}=0.68)$. In another study of 71 patients undergoing tractography integrated radiosurgery for AVMs (45 pyramidal tract, 22 optic radiation, and 13 arcuate fasciculus) with a median follow-up of 23 months, only one patient had new persistent morbidity from worsening of pre-existing dysaesthesia (15). Tractography is increasingly being integrated into radiosurgery planning for benign brain conditions (Figure $1)$.

In a feasibility study of 4 patients with low-grade glioma, Kovacs et al co-registered fMRI following acoustic, visual, somatosensory and numeral stimuli to a planning CT scan (89). The study showed that with fMRI based 3D conformal planning, radiotherapy dose to the superior and inferior temporal gyrus and lingual gyrus could be reduced by an average of $50 \%$. A subsequent study of 10 patients with brain tumours confirmed the role of fMRI in reducing dose to critical organs without compromising tumour target coverage (90).

A planning study has shown that integrating diffusion tensor tractography into IMRT planning has significantly reduced radiotherapy dose to the corticospinal tract in patients with glioblastoma (91). In another study of 20 patients with high-grade glioma, bilateral motor cortex and corticospinal tracts were marked using integrated DTI and BOLD-fMRI as organs at risk (OARs), which led to a reduction in the dose of radiotherapy using IMRT (92). Thus studies have shown that both DTI and BOLD-fMRI can be integrated into planning CT/MRI scan to delineate critical nerve tracks and eloquent regions for functional avoidance radiotherapy (figure 2).

\section{Challenges of integration of functional imaging for radiotherapy planning}

There are no long-term longitudinal studies correlating radiotherapy tolerance of various brain domains with neurocognitive dysfunction. One of the pre-requisites for use of functional avoidance radiotherapy is the robust understanding of the patterns of spread of individual brain tumours and the potential risk of relapse in an eloquent track or part of the brain. This necessitates carefully planned patterns of relapse studies which should be correlated with individual functional MRI scans.

While planning of radiotherapy using fMRI seems to be feasible, it is not certain whether the treatment can be delivered daily with high accuracy. Adaptive radiotherapy techniques using image guidance are evolving for a number of cancers. However, this technology has not been fully evaluated in brain tumours. While routine radiotherapy planning involves coregistrations of MRI scan with CT scan, the usual treatment verification is mainly based on 
bony anatomy. A robust method of delivery of functional avoidance radiotherapy using fMRI needs treatment verification with an MRI scan. MRI-LINAC is a new advance which integrates a verification MRI scan with the radiotherapy treatment machine to deliver MRIguided adaptive radiotherapy (93). This technology could be exploited further to deliver MRI guided, functional avoidance radiotherapy for paediatric brain tumours in the future.

\section{Future directions}

Radiotherapy techniques are now able to avoid potential areas of neurocognitive function when combined with optimal imaging. This needs to be assessed prospectively with neurocognitive function and tumour control as the primary outcomes. However, without proper knowledge of patterns of failure of different brain tumours, it would be unsafe to avoid radiotherapy to areas of brain which may harbour tumour.

With prospective studies we would be able to identify eloquent areas and tracts important in cognition and to correlate the effect of dose and volume of radiotherapy on specific cognitive domains. These studies would pave the way to functional image-guided risk-adapted radiotherapy for children with brain tumours.

While the concept of integration of functional imaging and tractography with modern radiotherapy to identify knowledge gaps in the correlation of radiotherapy parameters and neuro-cognitive function appears to be attractive in principle, there are a number of logistic challenges which can be addressed only with a prospective multi-stage collaborative approach (figure 3). Unfortunately, this approach will not yield a quick result, which can be integrated into the routine clinical practice. Nevertheless, clinicians should not be discouraged to embark on a path of slow and steady but incremental progress towards developing functional-image guided avoidance radiotherapy in children with brain tumour to maintain the highest quality of life without compromising the chances of cure. 
Table 1 Studies on the role of DTI in assessing neurocognitive dysfunction in children with brain tumours

\begin{tabular}{|c|c|c|c|}
\hline Study & No of patients & DTI finding & Summary of conclusion \\
\hline Malbott et al 2006(69) & $\begin{array}{l}8 \text { medulloblastoma patients } \\
\text { and controls }\end{array}$ & $\begin{array}{l}\text { Reduced IQ is associated with increased ADC } \\
\text { and reduced FA. Corpus callosum and anterior } \\
\text { and posterior limb of internal capsule has most } \\
\text { reduced FA. }\end{array}$ & $\begin{array}{l}\text { Reduced FA and increasesd ADC seen mostly in } \\
\text { anatomical regions and correlates with reduced } \\
\text { IQ. }\end{array}$ \\
\hline Khong et al 2006(68) & $\begin{array}{l}9 \text { medulloblastoma patients } \\
\text { (treated with RT and chemo) } \\
\text { vs controls. }\end{array}$ & $\begin{array}{l}\text { Reduced FA in all regions - even where } \\
\text { conventional imaging normal. Greater decrease } \\
\text { in FA correlated with earlier age of treatment, } \\
\text { longer interval from treatment and reduced } \\
\text { school performance }\end{array}$ & $\begin{array}{l}\text { Treatment related reduced FA. Correlates with } \\
\text { school outcomes. Age of treatment important } \\
\text { factor. }\end{array}$ \\
\hline Qiu et al 2007 (74) & $\begin{array}{l}22 \text { medulloblastoma survivors } \\
\text { and controls }\end{array}$ & $\begin{array}{l}\text { Calculated difference of FA and calculated } \\
\text { dose. Decreased FA has dose response. } \\
\text { Reduced FA frontal WM more than parietal } \\
\text { WM despite similar RT dose. }\end{array}$ & $\begin{array}{l}\text { Reduced FA has dose and anatomical location } \\
\text { relationship. }\end{array}$ \\
\hline Aukema et al 2009(20) & $\begin{array}{l}17 \text { patients treated for } \\
\text { medulloblastoma or ALL all } \\
\text { treated with chemotherapy }\end{array}$ & $\begin{array}{l}\text { Reduced FA compared to controls. Correlates } \\
\text { with neurocognitive decline from splenium and } \\
\text { body of corpus callosum. Correlates with motor } \\
\text { processing with inferior fronto-occipital } \\
\text { fasciculus. }\end{array}$ & $\begin{array}{l}\text { Reduced FA in treated patients. Regional } \\
\text { variation leads to differences in functional } \\
\text { deficit. }\end{array}$ \\
\hline $\begin{array}{l}\text { Rueckriegel et al } \\
2010(75)\end{array}$ & $\begin{array}{l}13 \text { patients with pilocytic } \\
\text { astrocytomas (not treated with } \\
\text { RT) and } 17 \text { medulloblastomas } \\
\text { (treated with RT) }\end{array}$ & $\begin{array}{l}\text { Decreased FA in medulloblastoma in midline } \\
\text { cerebellar structures, frontal white matter and } \\
\text { body of CC - the latter two not seen in } \\
\text { pilocytic astrocytoma. }\end{array}$ & $\begin{array}{l}\text { Difference between group was RT. Significant } \\
\text { difference in FA. No correlation with outcome. }\end{array}$ \\
\hline Brinkman et al 2012(45) & $\begin{array}{l}20 \text { patients with } \\
\text { medulloblastoma }\end{array}$ & $\begin{array}{l}\text { RAD (radial diffusivity) in the frontal lobes } \\
\text { was negatively correlated with shifting } \\
\text { attention and cognitive flexibility and FA in } \\
\text { parietal lobe was positively correlated with } \\
\text { working memory and }\end{array}$ & $\begin{array}{l}\text { Reduced white matter integrity in multiple brain } \\
\text { regions correlated with deterioration in executive } \\
\text { function }\end{array}$ \\
\hline Palmer et al 2012(94) & $\begin{array}{l}40 \text { patients with } \\
\text { medulloblastoma treated with }\end{array}$ & $\begin{array}{l}\text { Patients had significantly lower FA throughout } \\
\text { WM fibre tract compared to controls. Lower }\end{array}$ & $\begin{array}{l}\text { Commissural fibes in the corpus callosum are } \\
\text { negatively affected by disease and treatment }\end{array}$ \\
\hline
\end{tabular}




\begin{tabular}{|c|c|c|c|}
\hline & $\begin{array}{l}\text { surgery and radiotherapy } \\
\text { compared with healthy } \\
\text { controls }\end{array}$ & $\begin{array}{l}\text { FA within genu, body and splenium of the } \\
\text { corpus callosum is associated with lower } \\
\text { processing speed }\end{array}$ & $\begin{array}{l}\text { which leads to detrimental effects in cognitive } \\
\text { processing. }\end{array}$ \\
\hline Horska 2014(95) & $\begin{array}{l}8 \text { brain tumours and } 1 \text { ALL, } 9 \\
\text { normal developing children as } \\
\text { control }\end{array}$ & $\begin{array}{l}\text { Patients had } 24 \% \text { higher overall mean ADC in } \\
\text { the hippocampus compared with control }\end{array}$ & $\begin{array}{l}\text { Difference in tissue sensitivity to injury among } \\
\text { gray matter regions may exist. }\end{array}$ \\
\hline King 2015(96) & $\begin{array}{l}27 \text { patients (14 had } \\
\text { radiotherapy) compared with } \\
27 \text { healthy volunteers }\end{array}$ & $\begin{array}{l}\text { Lower FA in the white matter of the anterior } \\
\text { portion of corpus callosum, right middle } \\
\text { temporal and frontal regions in the radiotherapy } \\
\text { group and it correlated with intellectual } \\
\text { performance }\end{array}$ & $\begin{array}{l}\text { Lower white matter integrity leaders to lower } \\
\text { intellectual outcome. Radiotherapy and } \\
\text { chemotherapy may contribute to white matter } \\
\text { disruption }\end{array}$ \\
\hline Rueckriegel 2015(49) & $\begin{array}{l}18 \text { medulloblastomas vs. } 15 \\
\text { pilocytic astrocytomas. }\end{array}$ & $\begin{array}{l}\text { Changes in volume of WM: GM+CSF and } \\
\text { reduction of FA correlate with cognitive } \\
\text { function, IQ, processing speed and shifting } \\
\text { speed. }\end{array}$ & $\begin{array}{l}\text { Changes in FA and white matter volume loss } \\
\text { correlates with neuropsychology outcomes. }\end{array}$ \\
\hline
\end{tabular}


Figure 1 Examples of integration of tractography with radiosurgery for benign brain conditions: (A) trigeminal neuralgia and (B) thalamotomy for tremor (Courtesy of Prof $\mathrm{T}$ Kaprealian, UCLA Department of Radiation Oncology, Los Angeles, USA)
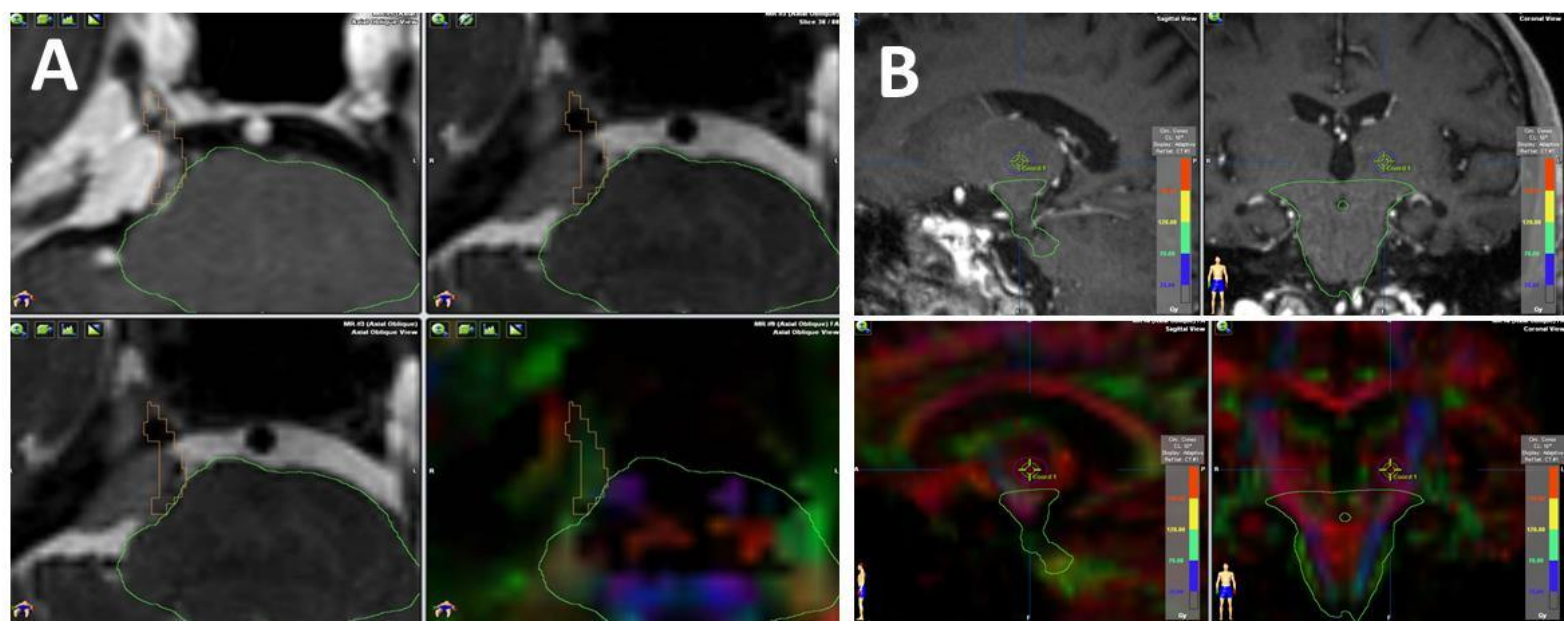
Figure 2 Functional BOLD MRI and tractography can be combined with anatomical MRI scan for treatment planning: (A) BOLD image after functional activation, (B\&C) position of tract in relation to tumour and the brainstem and (D) volumetric representation of tumour (pink), activation areas (green), and tracts (yellow) superimposed on the brain surface (reproduced with permission from BRAINLAB)

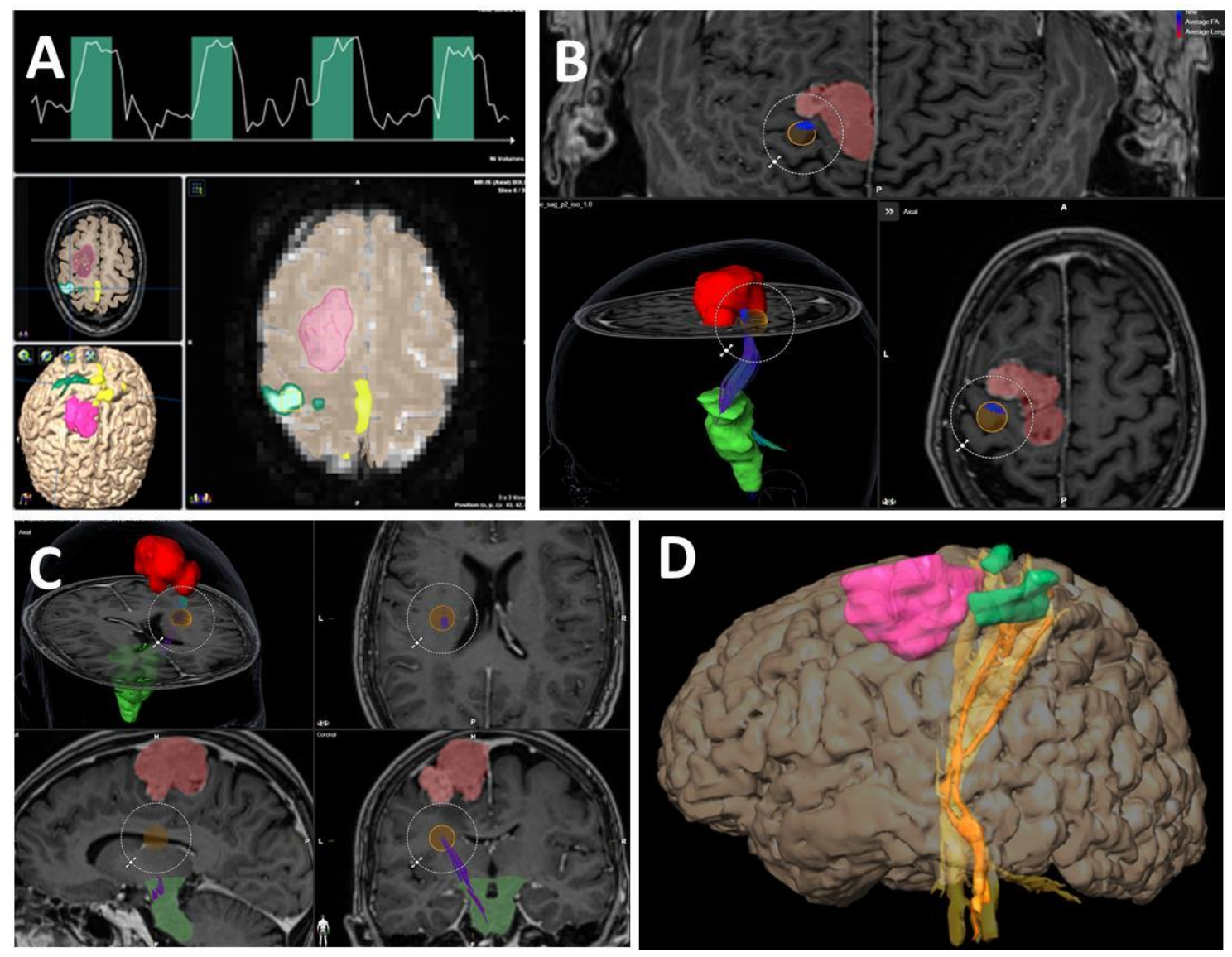


Figure 3 Schematic proposal for a multi-stage approach to develop functional avoiding mapping image-guided radiotherapy for paediatric brain tumour
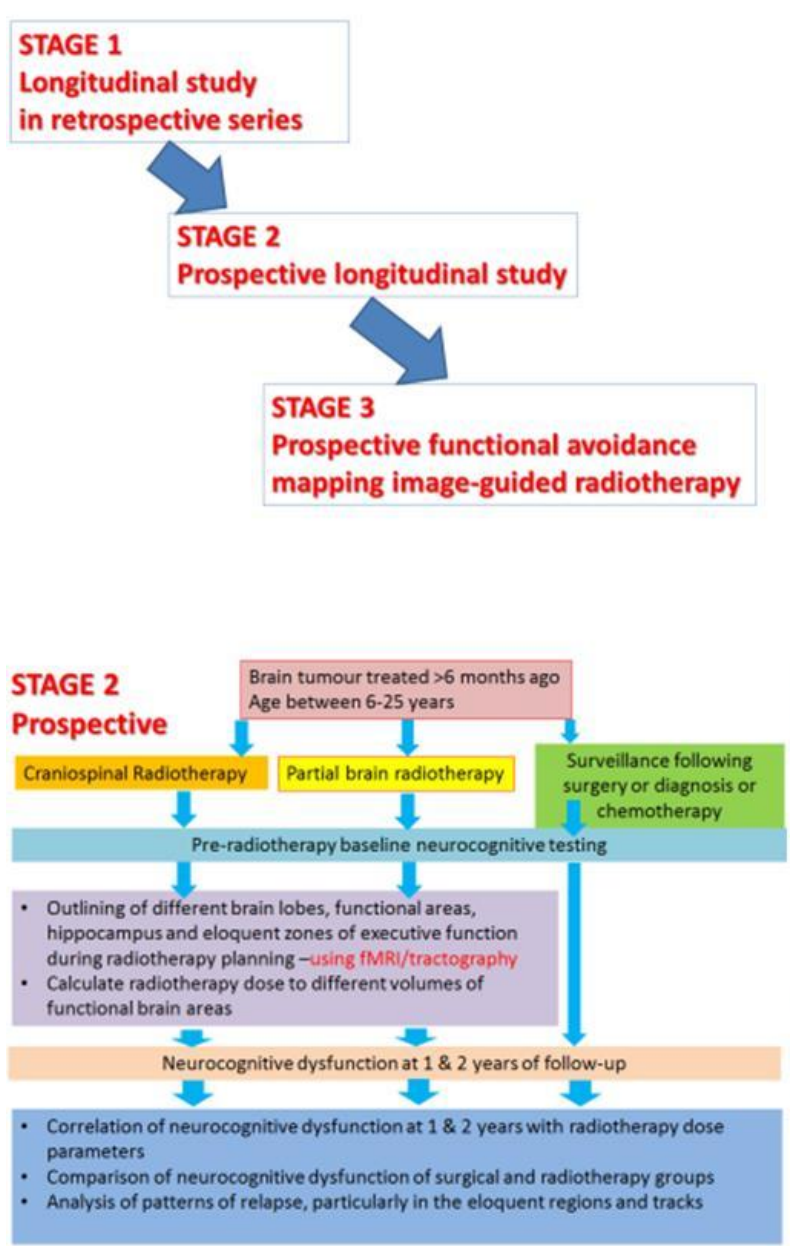
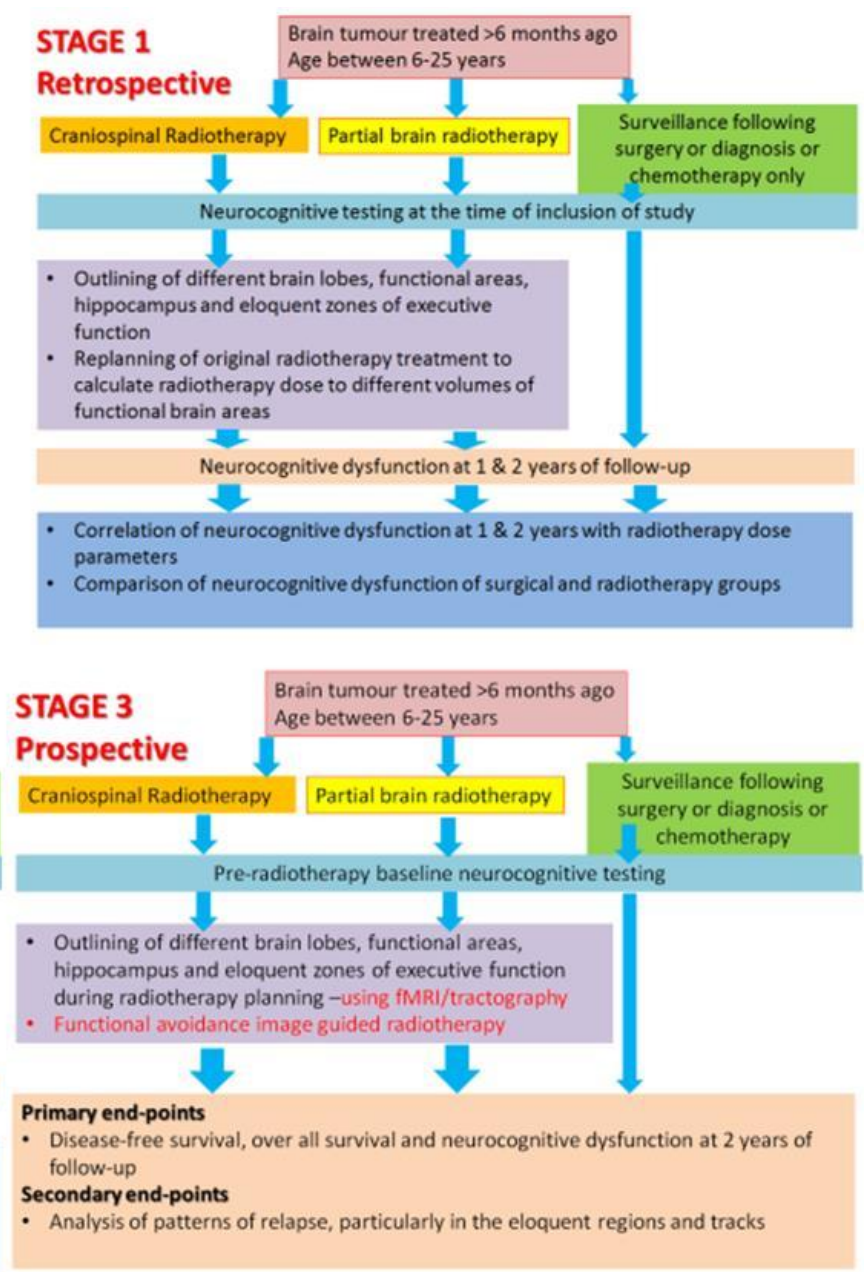


\section{References}

1. Ward E, DeSantis C, Robbins A, Kohler B, Jemal A. Childhood and adolescent cancer statistics, 2014. CA Cancer J Clin. 2014 Mar-Apr;64(2):83-103.

2. Segal D, Karajannis MA. Pediatric Brain Tumors: An Update. Curr Probl Pediatr Adolesc Health Care. 2016 Jul;46(7):242-50.

3. Ostrom QT, Gittleman H, Liao P, Rouse C, Chen Y, Dowling J, et al. CBTRUS statistical report: primary brain and central nervous system tumors diagnosed in the United States in 2007-2011. Neuro Oncol. 2015 Oct;16 Suppl 4:iv1-63.

4. Mulhern RK, Palmer SL, Merchant TE, Wallace D, Kocak M, Brouwers P, et al. Neurocognitive consequences of risk-adapted therapy for childhood medulloblastoma. J Clin Oncol. 2005 Aug 20;23(24):5511-9.

5. Palmer SL, Goloubeva O, Reddick WE, Glass JO, Gajjar A, Kun L, et al. Patterns of intellectual development among survivors of pediatric medulloblastoma: a longitudinal analysis. J Clin Oncol. 2001 Apr 15;19(8):2302-8.

6. Ullrich NJ, Embry L. Neurocognitive dysfunction in survivors of childhood brain tumors. Semin Pediatr Neurol. 2012 Mar;19(1):35-42.

7. Wefel JS, Noll KR, Scheurer ME. Neurocognitive functioning and genetic variation in patients with primary brain tumours. Lancet Oncol. 2016 Mar;17(3):e97-e108.

8. Ris MD, Packer R, Goldwein J, Jones-Wallace D, Boyett JM. Intellectual outcome after reduced-dose radiation therapy plus adjuvant chemotherapy for medulloblastoma: a Children's Cancer Group study. J Clin Oncol. 2001 Aug 1;19(15):3470-6.

9. Padovani L, Andre N, Constine LS, Muracciole X. Neurocognitive function after radiotherapy for paediatric brain tumours. Nat Rev Neurol. Oct;8(10):578-88.

10. Rutkowski S, Bode U, Deinlein F, Ottensmeier H, Warmuth-Metz M, Soerensen N, et al. Treatment of early childhood medulloblastoma by postoperative chemotherapy alone. $\mathrm{N}$ Engl J Med. 2005 Mar 10;352(10):978-86.

11. Merchant TE, Schreiber JE, Wu S, Lukose R, Xiong X, Gajjar A. Critical combinations of radiation dose and volume predict intelligence quotient and academic achievement scores after craniospinal irradiation in children with medulloblastoma. Int $\mathbf{J}$ Radiat Oncol Biol Phys. 2014 Nov 1;90(3):554-61.

12. Peet AC, Arvanitis TN, Leach MO, Waldman AD. Functional imaging in adult and paediatric brain tumours. Nat Rev Clin Oncol. 2012 Dec;9(12):700-11.

13. Spena G, Panciani PP, Fontanella MM. Resection of supratentorial gliomas: the need to merge microsurgical technical cornerstones with modern functional mapping concepts. An overview. Neurosurg Rev. 2015 Jan;38(1):59-70; discussion

14. Huang H, Ding Z, Mao D, Yuan J, Zhu F, Chen S, et al. PreSurgMapp: a MATLAB Toolbox for Presurgical Mapping of Eloquent Functional Areas Based on Task-Related and Resting-State Functional MRI. Neuroinformatics. 2016 May 24.

15. Koga T, Maruyama K, Kamada K, Ota T, Shin M, Itoh D, et al. Outcomes of diffusion tensor tractography-integrated stereotactic radiosurgery. Int J Radiat Oncol Biol Phys. 2012 Feb 1;82(2):799-802. 
16. Pantelis E, Papadakis N, Verigos K, Stathochristopoulou I, Antypas C, Lekas L, et al. Integration of functional MRI and white matter tractography in stereotactic radiosurgery clinical practice. Int J Radiat Oncol Biol Phys. 2010 Sep 1;78(1):257-67.

17. Attia A, Page BR, Lesser GJ, Chan M. Treatment of radiation-induced cognitive decline. Curr Treat Options Oncol. 2014 Dec;15(4):539-50.

18. Johnson BE, Grayson J, Makuch RW, Linnoila RI, Anderson MJ, Cohen MH, et al. Ten-year survival of patients with small-cell lung cancer treated with combination chemotherapy with or without irradiation. J Clin Oncol. 1990 Mar;8(3):396-401.

19. DeAngelis LM, Delattre JY, Posner JB. Radiation-induced dementia in patients cured of brain metastases. Neurology. 1989 Jun;39(6):789-96.

20. Aukema EJ, Caan MW, Oudhuis N, Majoie CB, Vos FM, Reneman L, et al. White matter fractional anisotropy correlates with speed of processing and motor speed in young childhood cancer survivors. Int J Radiat Oncol Biol Phys. 2009 Jul 1;74(3):837-43.

21. Balentova S, Adamkov M. Molecular, Cellular and Functional Effects of RadiationInduced Brain Injury: A Review. Int J Mol Sci.16(11):27796-815.

22. Nathan PC, Patel SK, Dilley K, Goldsby R, Harvey J, Jacobsen C, et al. Guidelines for identification of, advocacy for, and intervention in neurocognitive problems in survivors of childhood cancer: a report from the Children's Oncology Group. Arch Pediatr Adolesc Med. 2007 Aug;161(8):798-806.

23. Mulhern RK, Merchant TE, Gajjar A, Reddick WE, Kun LE. Late neurocognitive sequelae in survivors of brain tumours in childhood. Lancet Oncol. 2004 Jul;5(7):399-408.

24. de Ruiter MA, van Mourik R, Schouten-van Meeteren AY, Grootenhuis MA,

Oosterlaan J. Neurocognitive consequences of a paediatric brain tumour and its treatment: a meta-analysis. Dev Med Child Neurol. 2012 May;55(5):408-17.

25. Patel SK, Lo TT, Dennis JM, Bhatia S. Neurocognitive and behavioral outcomes in Latino childhood cancer survivors. Pediatr Blood Cancer. 2013 Oct;60(10):1696-702.

26. Apple DM, Fonseca RS, Kokovay E. The role of adult neurogenesis in psychiatric and cognitive disorders. Brain Res. 2016 Jan 19.

27. Taupin P. Neural progenitor and stem cells in the adult central nervous system. Ann Acad Med Singapore. 2006 Nov;35(11):814-20.

28. Greenberger BA, Pulsifer MB, Ebb DH, MacDonald SM, Jones RM, Butler WE, et al. Clinical outcomes and late endocrine, neurocognitive, and visual profiles of proton radiation for pediatric low-grade gliomas. Int J Radiat Oncol Biol Phys. 2014 Aug 1;89(5):1060-8.

29. Buckner RL. Functional-anatomic correlates of control processes in memory. J Neurosci. 2003 May 15;23(10):3999-4004.

30. Jokinen H, Ryberg C, Kalska H, Ylikoski R, Rostrup E, Stegmann MB, et al. Corpus callosum atrophy is associated with mental slowing and executive deficits in subjects with age-related white matter hyperintensities: the LADIS Study. J Neurol Neurosurg Psychiatry. 2007 May;78(5):491-6.

31. Morris RG, Moser EI, Riedel G, Martin SJ, Sandin J, Day M, et al. Elements of a neurobiological theory of the hippocampus: the role of activity-dependent synaptic plasticity in memory. Philos Trans R Soc Lond B Biol Sci. 2003 Apr 29;358(1432):773-86. 
32. Peiffer AM, Leyrer CM, Greene-Schloesser DM, Shing E, Kearns WT, Hinson WH, et al. Neuroanatomical target theory as a predictive model for radiation-induced cognitive decline. Neurology. 2013 Feb 19;80(8):747-53.

33. Scoville WB, Milner B. Loss of recent memory after bilateral hippocampal lesions. J Neurol Neurosurg Psychiatry. 1957 Feb;20(1):11-21.

34. Gondi V, Hermann BP, Mehta MP, Tome WA. Hippocampal dosimetry predicts neurocognitive function impairment after fractionated stereotactic radiotherapy for benign or low-grade adult brain tumors. Int J Radiat Oncol Biol Phys. 2012 Jul 15;83(4):e487-93.

35. Blomstrand M, Brodin NP, Munck Af Rosenschold P, Vogelius IR, Sanchez Merino G, Kiil-Berthlesen A, et al. Estimated clinical benefit of protecting neurogenesis in the developing brain during radiation therapy for pediatric medulloblastoma. Neuro Oncol. 2012 Jul;14(7):882-9.

36. Tsai PF, Yang CC, Chuang CC, Huang TY, Wu YM, Pai PC, et al. Hippocampal dosimetry correlates with the change in neurocognitive function after hippocampal sparing during whole brain radiotherapy: a prospective study. Radiat Oncol. 2015;10:253.

37. Kundapur V, Ellchuk T, Ahmed S, Gondi V. Risk of hippocampal metastases in small cell lung cancer patients at presentation and after cranial irradiation: a safety profile study for hippocampal sparing during prophylactic or therapeutic cranial irradiation. Int J Radiat Oncol Biol Phys. 2015 Mar 15;91(4):781-6.

38. Hong AM, Suo C, Valenzuela M, Haydu LE, Jacobsen KD, Reisse CH, et al. Low incidence of melanoma brain metastasis in the hippocampus. Radiother Oncol. 2014 Apr;111(1):59-62.

39. Sonderkaer S, Schmiegelow M, Carstensen H, Nielsen LB, Muller J, Schmiegelow K. Long-term neurological outcome of childhood brain tumors treated by surgery only. J Clin Oncol. 2003 Apr 1;21(7):1347-51.

40. Palmer SL, Hassall T, Evankovich K, Mabbott DJ, Bonner M, Deluca C, et al. Neurocognitive outcome 12 months following cerebellar mutism syndrome in pediatric patients with medulloblastoma. Neuro Oncol. 2010 Dec;12(12):1311-7.

41. Fouladi M, Chintagumpala M, Laningham FH, Ashley D, Kellie SJ, Langston JW, et al. White matter lesions detected by magnetic resonance imaging after radiotherapy and highdose chemotherapy in children with medulloblastoma or primitive neuroectodermal tumor. $\mathbf{J}$ Clin Oncol. 2004 Nov 15;22(22):4551-60.

42. Harila-Saari AH, Paakko EL, Vainionpaa LK, Pyhtinen J, Lanning BM. A longitudinal magnetic resonance imaging study of the brain in survivors in childhood acute lymphoblastic leukemia. Cancer. 1998 Dec 15;83(12):2608-17.

43. Iuvone L, Mariotti P, Colosimo C, Guzzetta F, Ruggiero A, Riccardi R. Long-term cognitive outcome, brain computed tomography scan, and magnetic resonance imaging in children cured for acute lymphoblastic leukemia. Cancer. 2002 Dec 15;95(12):2562-70.

44. Prust MJ, Jafari-Khouzani K, Kalpathy-Cramer J, Polaskova P, Batchelor TT, Gerstner ER, et al. Standard chemoradiation for glioblastoma results in progressive brain volume loss. Neurology. 2015 Aug 25;85(8):683-91.

45. Brinkman TM, Reddick WE, Luxton J, Glass JO, Sabin ND, Srivastava DK, et al. Cerebral white matter integrity and executive function in adult survivors of childhood medulloblastoma. Neuro Oncol. 2012 Sep;14 Suppl 4:iv25-36. 
46. Mulhern RK, Reddick WE, Palmer SL, Glass JO, Elkin TD, Kun LE, et al.

Neurocognitive deficits in medulloblastoma survivors and white matter loss. Ann Neurol. 1999 Dec;46(6):834-41.

47. Mulhern RK, Palmer SL, Reddick WE, Glass JO, Kun LE, Taylor J, et al. Risks of young age for selected neurocognitive deficits in medulloblastoma are associated with white matter loss. J Clin Oncol. 2001 Jan 15;19(2):472-9.

48. Carey ME, Haut MW, Reminger SL, Hutter JJ, Theilmann R, Kaemingk KL. Reduced frontal white matter volume in long-term childhood leukemia survivors: a voxel-based morphometry study. AJNR Am J Neuroradiol. 2008 Apr;29(4):792-7.

49. Rueckriegel SM, Bruhn H, Thomale UW, Hernaiz Driever P. Cerebral white matter fractional anisotropy and tract volume as measured by MR imaging are associated with impaired cognitive and motor function in pediatric posterior fossa tumor survivors. Pediatr Blood Cancer. 2015 Jul;62(7):1252-8.

50. Reddick WE, Taghipour DJ, Glass JO, Ashford J, Xiong X, Wu S, et al. Prognostic factors that increase the risk for reduced white matter volumes and deficits in attention and learning for survivors of childhood cancers. Pediatr Blood Cancer. 2014 Jun;61(6):1074-9. 51. Chen CM, Hou BL, Holodny AI. Effect of age and tumor grade on BOLD functional MR imaging in preoperative assessment of patients with glioma. Radiology. 2008 Sep;248(3):971-8.

52. Liu WC, Feldman SC, Schulder M, Kalnin AJ, Holodny AI, Zimmerman A, et al. The effect of tumour type and distance on activation in the motor cortex. Neuroradiology. 2005 Nov;47(11):813-9.

53. Hou BL, Bradbury M, Peck KK, Petrovich NM, Gutin PH, Holodny AI. Effect of brain tumor neovasculature defined by $\mathrm{rCBV}$ on BOLD fMRI activation volume in the primary motor cortex. Neuroimage. 2006 Aug 15;32(2):489-97.

54. Ruff IM, Petrovich Brennan NM, Peck KK, Hou BL, Tabar V, Brennan CW, et al. Assessment of the language laterality index in patients with brain tumor using functional MR imaging: effects of thresholding, task selection, and prior surgery. AJNR Am J Neuroradiol. 2008 Mar;29(3):528-35.

55. Kim MJ, Holodny AI, Hou BL, Peck KK, Moskowitz CS, Bogomolny DL, et al. The effect of prior surgery on blood oxygen level-dependent functional MR imaging in the preoperative assessment of brain tumors. AJNR Am J Neuroradiol. 2005 Sep;26(8):1980-5.

56. Bizzi A, Blasi V, Falini A, Ferroli P, Cadioli M, Danesi U, et al. Presurgical functional MR imaging of language and motor functions: validation with intraoperative electrocortical mapping. Radiology. 2008 Aug;248(2):579-89.

57. Picht T, Wachter D, Mularski S, Kuehn B, Brock M, Kombos T, et al. Functional magnetic resonance imaging and cortical mapping in motor cortex tumor surgery: complementary methods. Zentralbl Neurochir. 2008 Feb;69(1):1-6.

58. Ulmer JL, Krouwer HG, Mueller WM, Ugurel MS, Kocak M, Mark LP. Pseudoreorganization of language cortical function at fMR imaging: a consequence of tumorinduced neurovascular uncoupling. AJNR Am J Neuroradiol. 2003 Feb;24(2):213-7. 59. Roux FE, Boulanouar K, Lotterie JA, Mejdoubi M, LeSage JP, Berry I. Language functional magnetic resonance imaging in preoperative assessment of language areas: 
correlation with direct cortical stimulation. Neurosurgery. 2003 Jun;52(6):1335-45; discussion 45-7.

60. Rutten GJ, Ramsey NF, van Rijen PC, van Veelen CW. Reproducibility of fMRIdetermined language lateralization in individual subjects. Brain Lang. 2002 Mar;80(3):42137.

61. Morrison MA, Churchill NW, Cusimano MD, Schweizer TA, Das S, Graham SJ. Reliability of Task-Based fMRI for Preoperative Planning: A Test-Retest Study in Brain Tumor Patients and Healthy Controls. PLoS One. 2016;11(2):e0149547.

62. Hart MG, Ypma RJ, Romero-Garcia R, Price SJ, Suckling J. Graph theory analysis of complex brain networks: new concepts in brain mapping applied to neurosurgery. $\mathrm{J}$

Neurosurg. 2016 Jun;124(6):1665-78.

63. Marques P, Moreira P, Magalhaes R, Costa P, Santos N, Zihl J, et al. The functional connectome of cognitive reserve. Hum Brain Mapp. 2016 Sep;37(9):3310-22.

64. Pierpaoli C, Basser PJ. Toward a quantitative assessment of diffusion anisotropy. Magn Reson Med. 1996 Dec;36(6):893-906.

65. Bennett IJ, Madden DJ. Disconnected aging: cerebral white matter integrity and agerelated differences in cognition. Neuroscience. 2014 Sep 12;276:187-205.

66. Barnea-Goraly N, Menon V, Eckert M, Tamm L, Bammer R, Karchemskiy A, et al. White matter development during childhood and adolescence: a cross-sectional diffusion tensor imaging study. Cereb Cortex. 2005 Dec;15(12):1848-54.

67. Nagy Z, Westerberg H, Klingberg T. Maturation of white matter is associated with the development of cognitive functions during childhood. J Cogn Neurosci. 2004 Sep;16(7):1227-33.

68. Khong PL, Leung LH, Fung AS, Fong DY, Qiu D, Kwong DL, et al. White matter anisotropy in post-treatment childhood cancer survivors: preliminary evidence of association with neurocognitive function. J Clin Oncol. 2006 Feb 20;24(6):884-90.

69. Mabbott DJ, Noseworthy MD, Bouffet E, Rockel C, Laughlin S. Diffusion tensor imaging of white matter after cranial radiation in children for medulloblastoma: correlation with IQ. Neuro Oncol. 2006 Jul;8(3):244-52.

70. Schuitema I, Deprez S, Van Hecke W, Daams M, Uyttebroeck A, Sunaert S, et al. Accelerated aging, decreased white matter integrity, and associated neuropsychological dysfunction 25 years after pediatric lymphoid malignancies. J Clin Oncol. 2013 Sep 20;31(27):3378-88.

71. Khong PL, Kwong DL, Chan GC, Sham JS, Chan FL, Ooi GC. Diffusion-tensor imaging for the detection and quantification of treatment-induced white matter injury in children with medulloblastoma: a pilot study. AJNR Am J Neuroradiol. 2003 Apr;24(4):73440.

72. Khong PL, Leung LH, Chan GC, Kwong DL, Wong WH, Cao G, et al. White matter anisotropy in childhood medulloblastoma survivors: association with neurotoxicity risk factors. Radiology. 2005 Aug;236(2):647-52.

73. Nazem-Zadeh MR, Chapman CH, Chenevert T, Lawrence TS, Ten Haken RK, Tsien CI, et al. Response-driven imaging biomarkers for predicting radiation necrosis of the brain. Phys Med Biol. 2014 May 21;59(10):2535-47. 
74. Qiu D, Kwong DL, Chan GC, Leung LH, Khong PL. Diffusion tensor magnetic resonance imaging finding of discrepant fractional anisotropy between the frontal and parietal lobes after whole-brain irradiation in childhood medulloblastoma survivors: reflection of regional white matter radiosensitivity? Int J Radiat Oncol Biol Phys. 2007 Nov 1;69(3):84651.

75. Rueckriegel SM, Driever PH, Blankenburg F, Ludemann L, Henze G, Bruhn H. Differences in supratentorial damage of white matter in pediatric survivors of posterior fossa tumors with and without adjuvant treatment as detected by magnetic resonance diffusion tensor imaging. Int J Radiat Oncol Biol Phys. 2010 Mar 1;76(3):859-66.

76. Dellani PR, Eder S, Gawehn J, Vucurevic G, Fellgiebel A, Muller MJ, et al. Late structural alterations of cerebral white matter in long-term survivors of childhood leukemia. $\mathrm{J}$ Magn Reson Imaging. 2008 Jun;27(6):1250-5.

77. Edelmann MN, Krull KR, Liu W, Glass JO, Ji Q, Ogg RJ, et al. Diffusion tensor imaging and neurocognition in survivors of childhood acute lymphoblastic leukaemia. Brain. 2014 Nov;137(Pt 11):2973-83.

78. Leung LH, Ooi GC, Kwong DL, Chan GC, Cao G, Khong PL. White-matter diffusion anisotropy after chemo-irradiation: a statistical parametric mapping study and histogram analysis. Neuroimage. 2004 Jan;21(1):261-8.

79. Chapman CH, Nazem-Zadeh M, Lee OE, Schipper MJ, Tsien CI, Lawrence TS, et al. Regional variation in brain white matter diffusion index changes following chemoradiotherapy: a prospective study using tract-based spatial statistics. PLoS One. 2013;8(3):e57768.

80. Porto L, Preibisch C, Hattingen E, Bartels M, Lehrnbecher T, Dewitz R, et al. Voxelbased morphometry and diffusion-tensor MR imaging of the brain in long-term survivors of childhood leukemia. Eur Radiol. 2008 Nov;18(11):2691-700.

81. Oehlke O, Wucherpfennig D, Fels F, Frings L, Egger K, Weyerbrock A, et al. Whole brain irradiation with hippocampal sparing and dose escalation on multiple brain metastases: Local tumour control and survival. Strahlenther Onkol. 2015 Jun;191(6):461-9.

82. Hauswald H, Habl G, Krug D, Kehle D, Combs SE, Bermejo JL, et al. Whole brain helical Tomotherapy with integrated boost for brain metastases in patients with malignant melanoma-a randomized trial. Radiat Oncol. 2013;8:234.

83. Gondi V, Tolakanahalli R, Mehta MP, Tewatia D, Rowley H, Kuo JS, et al. Hippocampal-sparing whole-brain radiotherapy: a "how-to" technique using helical tomotherapy and linear accelerator-based intensity-modulated radiotherapy. Int J Radiat Oncol Biol Phys. 2010 Nov 15;78(4):1244-52.

84. Gondi V, Yock TI, Mehta MP. Proton therapy for paediatric CNS tumours improving treatment-related outcomes. Nat Rev Neurol. 2016 Jun;12(6):334-45.

85. Yock TI, Yeap BY, Ebb DH, Weyman E, Eaton BR, Sherry NA, et al. Long-term toxic effects of proton radiotherapy for paediatric medulloblastoma: a phase 2 single-arm study. Lancet Oncol. 2016 Mar;17(3):287-98.

86. Aoyama H, Kamada K, Shirato H, Takeuchi F, Kuriki S, Iwasaki Y, et al. Integration of functional brain information into stereotactic irradiation treatment planning using magnetoencephalography and magnetic resonance axonography. Int J Radiat Oncol Biol Phys. 2004 Mar 15;58(4):1177-83. 
87. Maruyama K, Kamada K, Shin M, Itoh D, Masutani Y, Ino K, et al. Optic radiation tractography integrated into simulated treatment planning for Gamma Knife surgery. J Neurosurg. 2007 Oct;107(4):721-6.

88. Koga T, Shin M, Maruyama K, Kamada K, Ota T, Itoh D, et al. Integration of corticospinal tractography reduces motor complications after radiosurgery. Int J Radiat Oncol Biol Phys. 2011 May 1;83(1):129-33.

89. Kovacs A, Toth L, Glavak C, Lakosi F, Hadjiev J, Bajzik G, et al. Integrating functional MRI information into radiotherapy planning of CNS tumors-early experiences. Pathol Oncol Res. 2011 Jun;17(2):207-17.

90. Kovacs A, Toth L, Glavak C, Liposits G, Hadjiev J, Antal G, et al. Integrating functional MRI information into conventional 3D radiotherapy planning of CNS tumors. Is it worth it? J Neurooncol. 2011 Dec;105(3):629-37.

91. Igaki H, Sakumi A, Mukasa A, Saito K, Kunimatsu A, Masutani Y, et al. Corticospinal tract-sparing intensity-modulated radiotherapy treatment planning. Rep Pract Oncol Radiother. 2014 Sep;19(5):310-6.

92. Wang M, Ma H, Wang X, Guo Y, Xia X, Xia H, et al. Integration of BOLD-fMRI and DTI into radiation treatment planning for high-grade gliomas located near the primary motor cortexes and corticospinal tracts. Radiat Oncol. 2015;10:64.

93. Lagendijk JJ, van Vulpen M, Raaymakers BW. The development of the MRI linac system for online MRI-guided radiotherapy: a clinical update. J Intern Med. 2016 Aug;280(2):203-8.

94. Palmer SL, Glass JO, Li Y, Ogg R, Qaddoumi I, Armstrong GT, et al. White matter integrity is associated with cognitive processing in patients treated for a posterior fossa brain tumor. Neuro Oncol. 2012 Sep;14(9):1185-93.

95. Horska A, Nidecker A, Intrapiromkul J, Tannazi F, Ardekani S, Brant LJ, et al. Diffusion tensor imaging of deep gray matter in children treated for brain malignancies. Childs Nerv Syst. 2014 Apr;30(4):631-8.

96. King TZ, Wang L, Mao H. Disruption of White Matter Integrity in Adult Survivors of Childhood Brain Tumors: Correlates with Long-Term Intellectual Outcomes. PLoS One. 2015;10(7):e0131744. 
Click here to download high resolution image
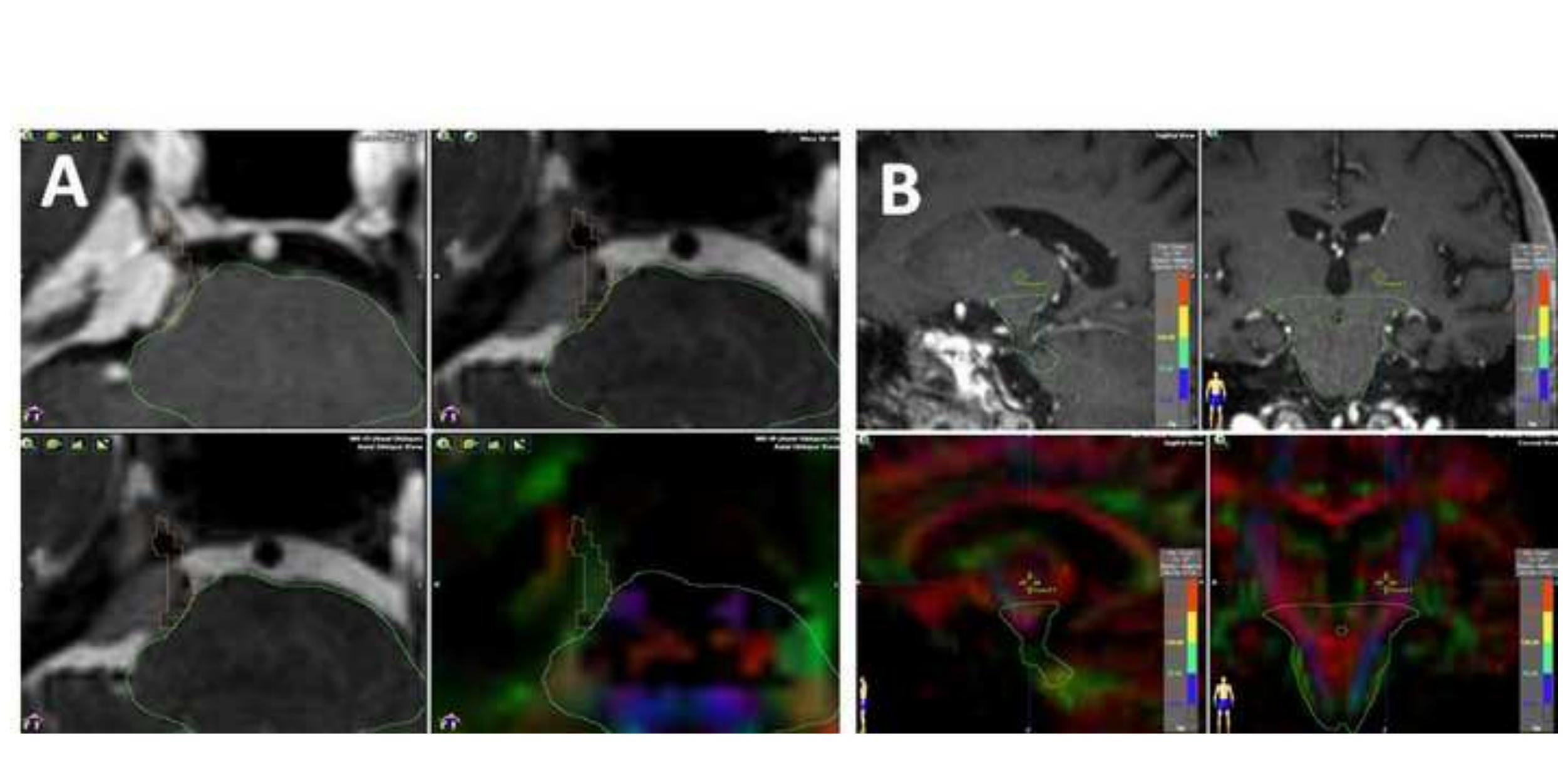

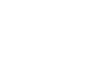

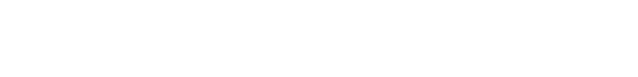


Click here to download high resolution image
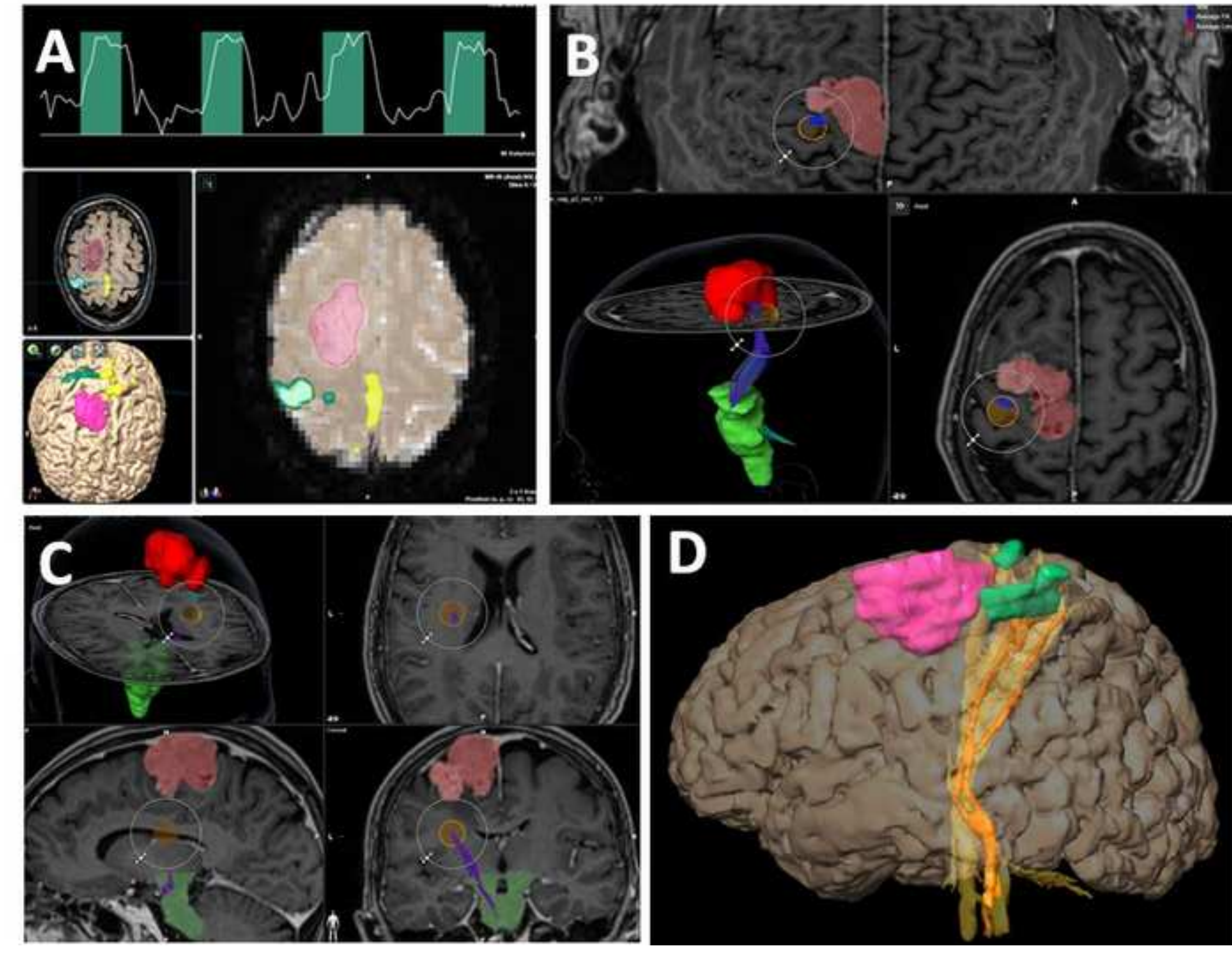


\section{STAGE 1}

Longitudinal study

in retrospective series

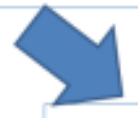

\section{STAGE 2}

Prospective longitudinal study

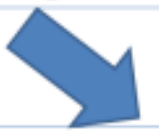

STAGE 3

Prospective functional avoidance mapping image-guided radiotherapy

\section{STAGE 1 \\ Retrospective}

Craniospinal Radiotherapy

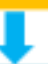
ge between $6-25$ years

months ago 1

- Outlining of different brain lobes, functional areas, hippocampus and eloquent zones of executive function

- Replanning of original radiotherapy treatment to calculate radiotherapy dose to different volumes of functional brain areas

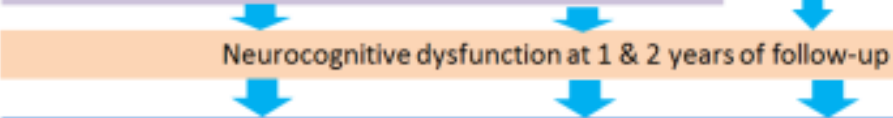

- Correlation of neurocognitive dysfunction at $1 \& 2$ years with radiotherapy dose parameters

- Comparison of neurocognitive dysfunction of surgical and radiotherapy groups

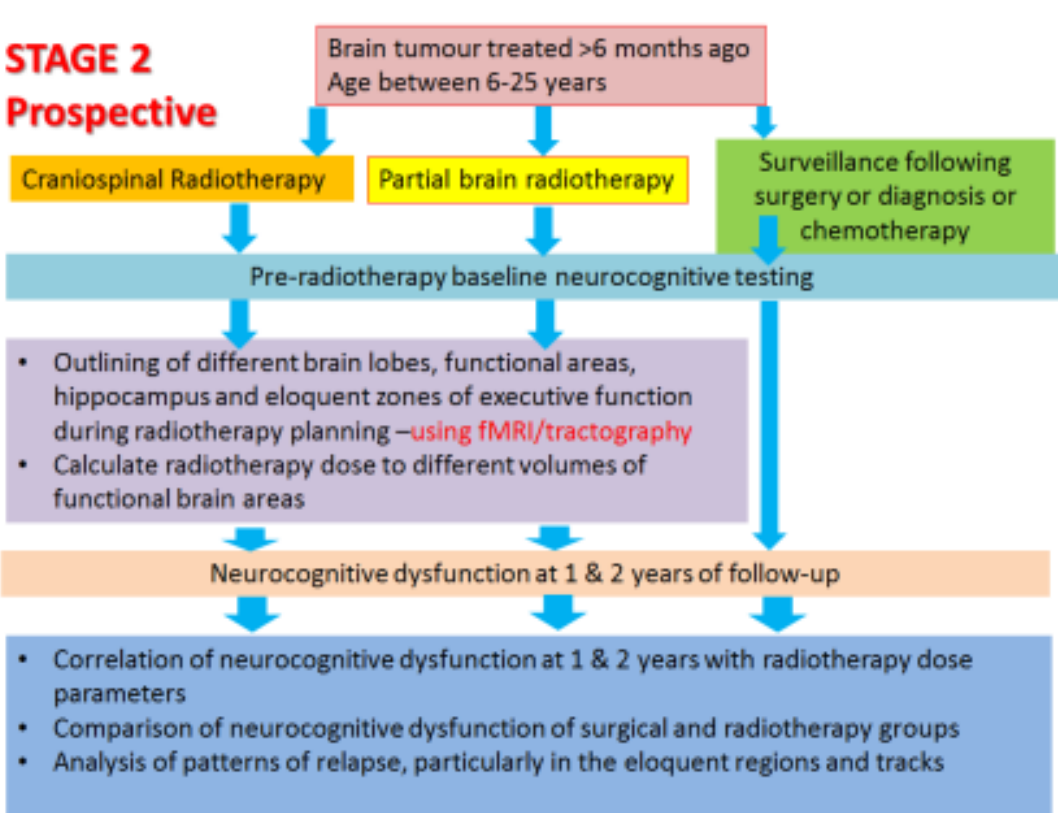

